This is an Accepted Manuscript version of an article published in Journal for the Study of

Religion, Nature \& Culture. The final Published Version is available online at:

http://dx.doi.org/ 10.1558/jsrnc.18831".

\title{
Political Ecology of Shifting Cosmologies and Epistemologies among Berber Agro- Sylvo-Pastoralists in a Globalizing World
}

\author{
Pablo Dominguez
}

\begin{abstract}
Laboratory for the Analysis of Socio-Ecological Systems in a Global World / Antropologia i Historia de les Identitats Socials i Politiques

Universitat Autónoma de Barcelona, 08193 Cerdanyola del Vallès - Barcelona, Spain ${ }^{1}$ eco.anthropologies@gmail.com
\end{abstract}

\begin{abstract}
This article examines how local religious traditions and environmental management interact with each other, as well as how both relate to new globalizing influences such as emerging state structures and ideologies, mass media, migrations, market integration, tourism, NGOs, modernist conceptions of nature, and present Islamic movements. Through an ethnographic study of the Berber Mesioua tribe of the Moroccan High Atlas, I focus on the agdal, a locally produced agro-sylvo-pastoral governance system prohibiting access to particular natural resources for a given period in order to optimize its yield and assure its sustained and equitable use. The integration of agdals into local religiosity and their associated ethics entail a local conservationist and egalitarian set of principles. I conclude that, strained by the political forces implicated in the globalization of cosmologies and epistemologies, the replacement of local world views and the decline of the agdal governance system are interlinked. The consequences include increasing environmental degradation and social inequality.
\end{abstract}

\section{Keywords}

Agro-sylvo-pastoralism, Agdals, Cosmologies, Globalization, Morocco

\section{Introduction}

Scientists broadly agree on the rejection of generalizing the ecologically noble savage theory (Redford 2010). Nevertheless, and in concrete contexts, numerous authors have underlined the links between indigenous peoples' and local community based environmental managements deeply embedded in a diversity of cultural and religious traditions, with the long-term sustainment of the social and bio-physical systems on which they rely (Steward 1955; Rappaport 1968; Lansing 1987; Posey and Balee 1989; Toledo 1992; Ostrom 1999; Auclair and Alifriqui 2006; Berkes 2008). Despite this voluminous academic research repeatedly demonstrating such inextricable biocultural links, there remains a gap in the dearth of research

\footnotetext{
${ }^{1}$ Complementary affiliations: Centre for Biocultural Diversity, School of Anthropology and Conservation, University of Kent, Canterbury, Kent CT2 7NR (United Kingdom); Laboratoire population-environnement-développement, Aix-Marseille Université, Centre Saint-Charles, Case 10, 3, place Victor Hugo, 13331 Marseille cedex 3 (France).
} 
investigating the concrete ways in which these long-held relations are now being affected by globalization. Such criticism is particularly relevant in Morocco, where detailed focus on the interrelations between global changes and customary communal management regimes are surprisingly rare despite the many changes affecting an immense diversity of communally and ritually regulated systems (Simenel 2004; Auclair and Alifriqui 2012). In this context, the agdal systems--the managerial/governance forms of agro-sylvo-pastoral resources implemented by local communities of Morocco, mainly speaking different Berber dialects or languages, embedded in a long religious tradition but currently undergoing major changes linked to globalization--need to be better understood in order to fill the abovementioned theoretical and geographical gap.

The present article is based on eco-anthropological fieldwork conducted intermittently between 2003 and 2008 throughout all agro-sylvo-pastoral seasons adding up to one full year among the Berber Mesioua tribe (High Atlas of Marrakesh, Morocco) and mainly on its pastoral territory of Yagur (see figure 1 below), which is governed by the agdal, with a return in 2012 for reverification. The agdal system that manages the Yagur territory consists (agronomically speaking) of prohibiting herding access to the collective pastures for an effective period of two to three months. The primary motivation for this is to allow the grasses to grow and reproduce during the most critical period of their development (mainly the local spring from March to June-July) in order to assure conservation of the ecosystems and thus permit their use year after year. A second but no less important motivation for this agdal prohibition is to assure a more equal access to local natural resources than a simple open access regime, as all users of the Yagur collectively decide its rules of management according to the interests of the community's majority. This agdal prohibition period of the Yagur territory was traditionally legitimized and supported by long-held religious beliefs associated with the main local sufi saint, Sidi Boujmaa, and his descendants, who make up a religious brotherhood (zawiya) and were generally considered as sufi saints themselves. ${ }^{2}$

Nevertheless, in light of new influences such as modern state structures and ideologies, mass media, migrations, market integration, tourism, NGOs, modernist conceptions of nature and global Islamic movements, the religious beliefs of the Mesioui and the natural resource management system of the agdal of Yagur are undergoing major transformations. These transformations are mainly related to the substitution of the agdal by external ways of thinking and organizing, all at the same time as local economic inequalities develop and biological diversity diminishes on the Yagur (Dominguez 2010). In this context, my main research hypothesis is that strained by the forces of globalization, the replacement of the local cosmology and the decline of the traditional agdal natural resource management system are interlinked, and at the same time, these transformations are key drivers of the increasing social inequalities and environmental degradation in the area.

\section{Human Geography}

This study was carried out in the Moroccan High Atlas of Marrakesh, among the group of Mesioua people who occupy the highest and most mountainous areas of the tribe's territory and who are locally named 'the mountain Mesioui', as they are referred to hereafter. Like all inhabitants of the High Atlas of Morocco, the mountain Mesioui have an old system of earth terracing used for orchards (hortus), cereal agriculture (agro), trees for fruit and wood (sylvo) and pasturing (saltus) that is most often intensely complemented by an elaborate irrigation system able to produce the greatest possible yield out of the relatively scarce hydrologic

\footnotetext{
${ }^{2}$ In Morocco, a sufi saint is generally a deceased Muslim mystic (sufi) teacher who led a Koranic school and became a saint after death.
} 
resources. The lower mountain slopes are covered with shrub vegetation up to about 1,000 meters above sea level (about 3,300 feet) followed by rather open and overexploited Mediterranean forests dominated by Holm Oak (Quercus ilex) and Prickly Juniper (Juniperus oxycedrus) up to $2,500 \mathrm{~m}$ (8,200 feet). The cultivation of cereals such as corn, wheat, barley and millet along with some fruit trees such as olive, apricot, apple and plum trees, mainly by the banks of river beds, coexists with the aforementioned shrubs and forests up to a maximal height of 2,000m (6,600 feet). High altitude steppes are mainly found from 2,500 meters up to the highest point at 3,600m (11,800 feet), with a very occasional presence of some old and twisted Spanish Juniper trees (Juniperus thurifera), which are very degraded as a result of the extreme conditions and intense human use. Finally, dense green grass and herb pastures are generally found on the flattest areas and little valleys above $1,900 \mathrm{~m}(6,200$ feet $)$. Relatively small in surface area compared to other vegetal formations, these pastures are nevertheless one of the most important resources of the mountain Mesioua (although not the only) and one of the main reasons motivating the prohibition of pastoral access to the territory in order to protect them.

To a great extent, the Mesioui maintain the oldertribal organization characterized by an interlocking network (neither strict nor completely fluid) of different social groups that interact according to common interests and needs (Gellner 1969). Thus, the mountain Mesioui people continue to organize themselves into tribal factions (taqbilt), sub-factions (mouda), villages (douar), lineages (ikhs) and nuclear families (takat). At the highest social grouping, they are divided into five factions (Ait Oucheg, Ait Inzal, Ait Wagoustite, Ait Tighdouine and Ait Zat), totaling almost 25,000 people in nearly 100 villages and hamlets, most of which are interlinked by kin ties within each grouping level. The jmaas are the traditional assemblies or councils of elders existing at almost all social levels (ikhs, douar, mouda, taqbilt and the whole mountain Mesioui group) that function as the main institution for local governance, even if they are not always legally recognized by the state. These jmaas regulate all collective labor, natural resource management, festivities, religious affairs and other central activities of everyday social life. Agro-sylvo-pastoralism is central to the economy of these populations, and as a mean it provides over two thirds of the locals' income (Bellaoui 1989). The mountain Mesioui people commonly speak tachelhit, a South-Moroccan Berber dialect.. However, practically all the men also speak Arabic. They learn it through school, which first arrived in the 1990s, the media (mainly radio but also television), interactions with the administration, as well as social and professional relationships out of the valley. Nevertheless, since women in the high Zat valley basin only mainly learn Arabic through the media which they manage to follow less than men in any case, and school which they generally finish at an earlier age than men in order to help with domestic work, they tend to be much less proficient in this second language, especially the oldest of them. 


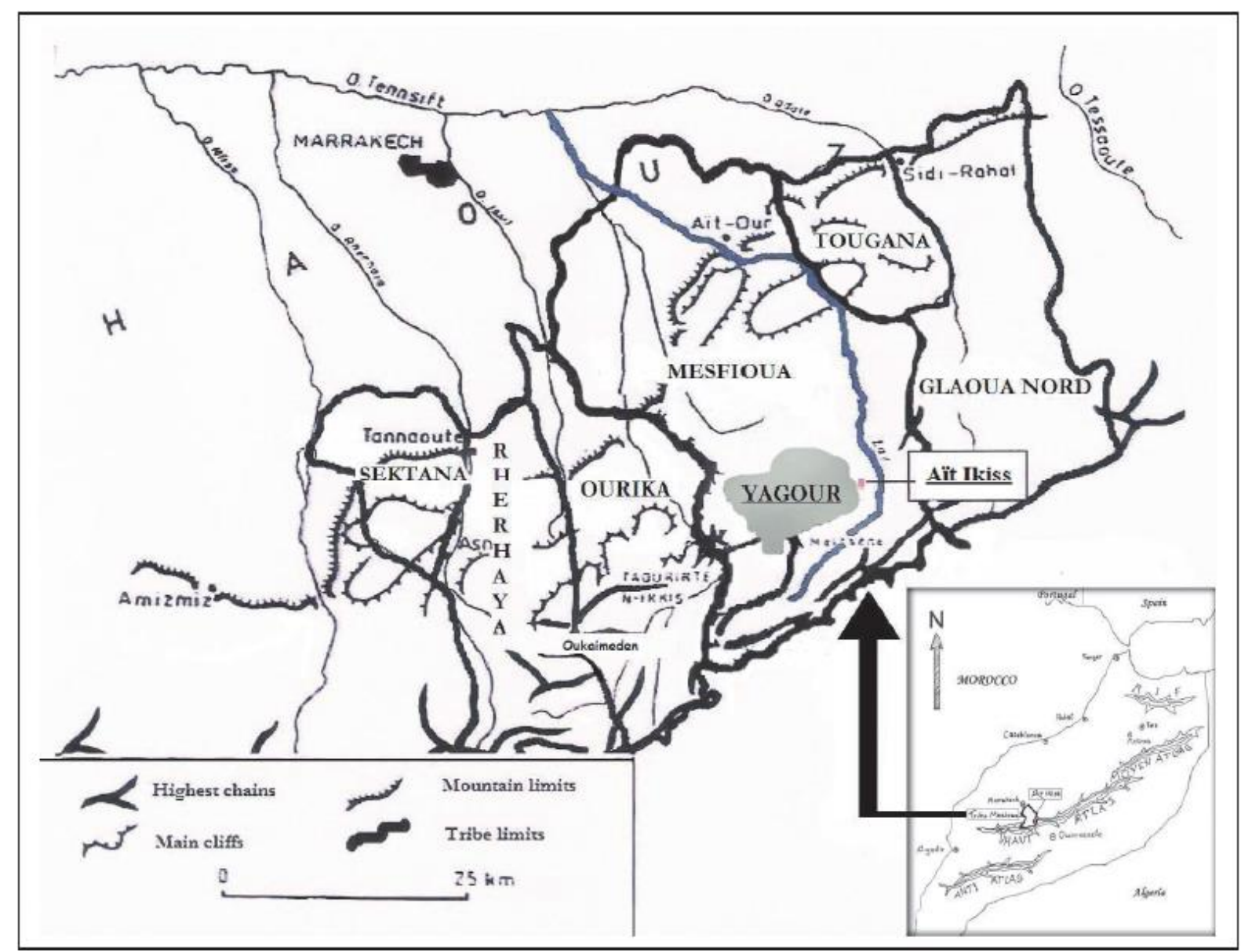

Figure 1: Location of the study area (map based on F. Lafuente 1968). 


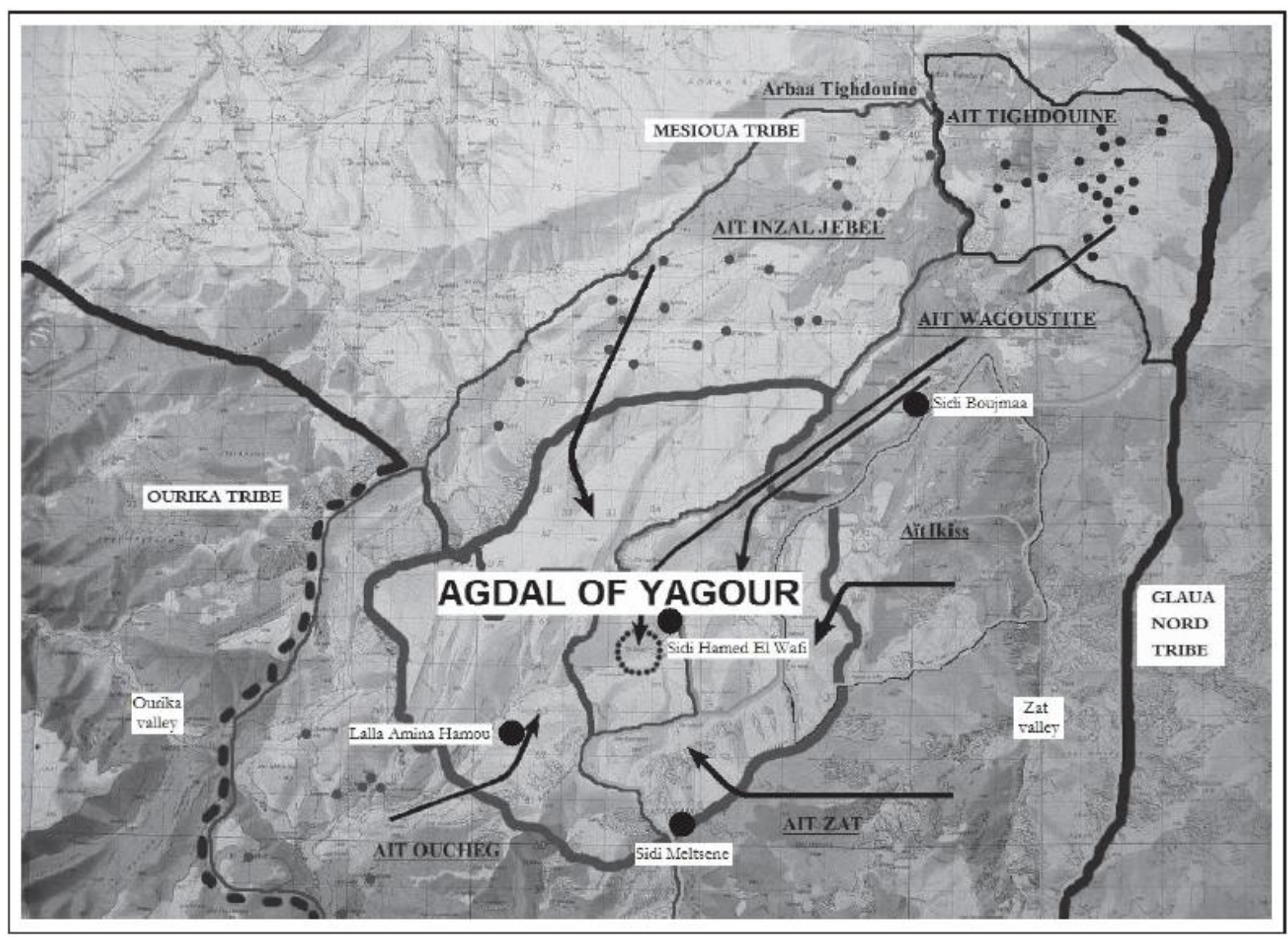

Figure 2: Mesioua tribal factions using the Yagur (map based on Ministère agriculture, 1977).

The geographical delimitation of my study area is composed by the Yagur pastoral territory, making up approximately 70 square kilometers, and the lands associated with it by transhumance, adding altogether up to more than 350 square kilometers. . At less than $50 \mathrm{~km}$ from Marrakesh in a straight line, but very difficult to access, ${ }^{3}$ the Yagur is a geographical unit centered on the morphological plateau of the same name composed of relatively flat lands of Permian-Triassic red sandstone, which produce thick and fertile soils that allow the growth of pastures of great quality for local herders. Located in the high mountains between $1,900 \mathrm{~m}$ (6,300 feet) and 3,600m (11,800 feet), this area is covered by snow all winter and subject to an agdal prohibition during spring every year. Hence, the Yagur is especially used as a pastureland in summer. During this period, as many as one thousand families make use of this space. Herding access to the collective pastures is forbidden from approximately 28 March to sometime in June or the beginning of July, mainly depending on each year's rainfall (the more rainfall the more available pastures elsewhere and thus the later the opening of the Yagur). The exact dates can vary largely, by as much as two months from year to year, and in years of extreme drought, access to the Yagur can be granted even before the month of June, in the last weeks of May. Nevertheless, despite its great importance for local society and being at the heart of the mountain Mesioui territory, the Yagur is only part of a larger agro-economic system comprising almost fifty douars (village units). In fact, its opening dates condition those of other big neighboring tribal agdals, as well as smaller village agdals, which in total can add up to more than one hundred agdals within the territory of the mountain Mesioui people.

\footnotetext{
${ }^{3}$ Only one sand trail that opens one or two months per year makes it reachable by $4 \times 4$ vehicles; others access it via mule tracks or through even less equipped paths.
} 


\section{The Agdal Concept}

An agdal prohibition can be described as a social institution comprising both the rules and regulations related to a given natural resource, as well as the processes by which they are established and applied. These rules and processes are agreed between local communities which have the right to establish the opening and closing of certain spaces in order to optimize their natural resource production in a relatively egalitarian way and assure its continuity over time. This practice ensures sustainable use as it is only possible to consider utilizing biomass consumption once the flowering and reproduction of key pastoral species is assured, without jeopardizing the seeds for the following generations (Alaoui 2009). The spaces, dates and resources affected by this prohibition, as well as the processes by which they are established and applied, are enforced by a different tribal council (mountain Mesioui jmaa, tribal faction jmaa, sub-faction jmaa, village jmaa or lineage jmaa) according to the resource to be managed in each case, the community size affected and in agreement with each local history, territorial heritage, and economic strategy.

The intense participation in the enforcement of the agdal prohibitions by the local population can be understood as a key social tool for enhancing local economy. Various small scale studies have revealed that the contribution of areas collectively managed by the agdals can be a positive addition to a community's livelihood. In the case of fodder leaves coming from the forests of Holm Oak (Quercus ilex) in villages of the Ait Bouguemez tribe (150 kilometers north-east of Marrakesh), which are managed by agdals prohibiting leaf extraction during the months without snow, Genin et al. (2012) found that they represent a key complementary economic resource opportunity during the snow period (when these forest agdals open) because other pastoral resources (herbs, bushes, etc.) are covered and inaccessible, frozen or simply dormant. Also, in certain villages, the rights of access to the pastoral agdals are exchanged for rights of water use between neighboring tribal groups in periods of scarcity (El Gueroua 2005). At the same time, in the forest agdal of the village of Ait Ourhayn (Mesioua tribe), herders from nearby villages without such well conserved forests buy loads of leaves and wood during snow periods, providing the Ait Ourhayn people with a complementary monetary income throughout the winter (Dominguez 2010). In this same case study, the contribution of the agdal-managed summer pasture of the Yagur was estimated at twelve percent of the overall family income, including migrant remittances, and approximately eighteen percent of the overall agro-pastoral income. Yagur agdal-managed pastures also contribute to farmers' agricultural enrichment through the recycling of nitrates which are manually returned from the highland animal folds to the lower agricultural soils in order to fertilize them (Demay 2004). ${ }^{4}$

In bio-physical terms, as several ecologists have indicated, the implementation of the agdals seems to have particularly beneficial effects on plant cover, preventing erosion and supporting biodiversity conservation (Kerautret 2005; Hammi et al. 2007; Alaoui 2009; Montès et al. 2012). For example, analyses of aerial and satellite photographs since 1964 by Hammi et al. (2007) have shown how forest vegetation in the Ait Bougmez persists, or has even increased, in areas subjected to agdal regulations, whereas in non-agdal areas where natural resources are freely harvested, there is a net reduction of forests. Almost the entire deforested areas at this study site (21.5 percent reduction of forest surface since 1964), occurs in non-agdal areas only. In addition, Montès et al. (2012) have demonstrated how the agdal management of the Ait Bouguemez forests has contributed not only to augment forest cover, but to conserve the soils

\footnotetext{
${ }^{4}$ In fact the soil's lack of nitrates is one of the most important limiting factors of the productivity of the local agro-pastoral system of the mountain Mesioui.
} 
and the diversity of plants and insects. Moreover, in her work, Alaoui (2009) has shown the proactive conservation of certain plant species through agdal prohibitions, in pastures such as the Oukaïmeden, which are close and very similar to the Mesioui summer pastures, particularly the Yagur. Dominguez and Hammi (2010) have also revealed a higher number of species present in the more traditional agdal-managed areas of the Yagur than in less intensely agdalmanaged areas. In areas surrounding the Yagur several spaces, particularly cemeteries, which are called tagdalt (small agdal) can be found. They have abundant vegetation and are permanently protected from grazing animals and from any removal due to the taboos that affect the use of these sacred places. And last but not least, like everywhere in the High Atlas Mountains, around the Yagur there also are many agdals of different types regulating the access to resources as varied as pastures, forests, orchards, cereal fields, and cemeteries, among others. Since the richness and type of botanical species varies due to agdal use rules (i.e. depending on the resource and population, some agdals open earlier and some open later), this produces a mosaic of varying ecosystems within the territory of the Mesioua tribe around the Yagur that augments the biological diversity of the region, both at the species and habitat levels (Dominguez 2010). Because this great variety of different agdal-managed spaces are more abundant in vegetation than those surrounding areas that are not agdal-managed, they serve as seed distribution points.

New national level conservation herding and forestry strategies are trying to enlist what they call 'the local population's participation'. The agdals should be considered a paradigmatic example for these participatory processes that have been put forward in the last two decades, as the agdal customary rules of collective use of the territory have always prevailed in the governance of Mesioui territory. ${ }^{5}$ However, there is still no official statement either assigning a specific status to these agdals or giving them any particular support. Indeed, because of generalist regulatory initiatives more focused on receiving international endorsement and cooperation funds, things do not change much. Continuity prevails with the environmental management practices of colonial and post-colonial administrations (Davis 2005). Since it has generally only been truly tested in different pilot experimental projects, 'local population's participation' remains, at least in the Yagur area, a vague notion that does not seem to go beyond these pilot projects in other sites. Indeed, the State's tepid support for local population's participation seems more of a new dialectic procedure to better achieve the same managerial objectives of old conservation policies grounded in outmoded climax theories and ideas about pristine nature, still defended by many global nature conservation organizations(Benabid 2000).

The local consequence of this dialectic is that during these last two decades, the public administration has continuously intervened through non-negotiated processes to forbid the mountain Mesioui people access to certain parts of their own territory, while promoting programs for reforestation, soil conservation or the construction of recreational landscapes for tourism. These initiatives compete with local populations for the same natural resources on which they are highly dependent and violent opposition from farmers sometimes arises, as occurs in other sites of the High Atlas (Auclair and Alifriqui 2006). While the discourse of forestry officials is founded on ideas of 'progress' and 'modernity' as opposed to 'archaism', in the case of local populations their discourse reveals the underlying idea of 'threat' to their existence and resistance. The narratives that are deployed by the different protagonists are a perfect arena to unveil antagonist worldviews and ideological referents.

\footnotetext{
${ }^{5}$ Such rules for collective use entail decisions about the opening and closing dates of the different agdals, decisions about the resources to which access has to be prohibited, decisions about the type of sanctions which have to be imposed on the offenders of the different prohibitions, etc.
} 
For example, in 2005 a group of Ait Oucheg people at the West of the Yagur were forbidden to herd in the area of Oughi-Tadrart. The forestry officials hoped this would combat erosion and dangerous floods that had caused serious damages in the past. Meanwhile, local herders saw this prohibition as an aggression against their means of survival as their already fragile common pool of pastoral resources was reduced, while they deeply doubted the efficacy of the forestry department's solutions to facing natural risk. Moreover, the opposing views and unequal power relations between state officials and villagers were a favorable context for the development of corruption. For example, in the upper Zat river there was an official prohibition on cutting trees for timber imposed by the Department of Water and Forests, but it seems that in every village (as I observed in my own fieldwork), locals meet publicly in a jmaa at least once a year to organize the collection of funds that will be paid to the forester in order to have 'the field free' to cut wood for their needs.

At the same time, the places and natural resources that local transhumant agro-sylvopastoralists manage through the agdals are being increasingly confronted with the demands of the surrounding urban society whose members also hold other views on the appropriate use of the territory, especially affinities with recreational tourism. For example, in recent years, foreign investors have shown great interest in areas that offer what Descola (2005) calls a vision of 'wild' nature. In 2008, a group from the United Arab Emirates planned to create a massive tourist resort, including the development of ski slopes, an 18-hole golf course promoted as the highest in Africa, a high altitude running track for the training of elite athletes, eleven hotels and many residences on the Oukaïmeden agdal just $10 \mathrm{~km}$ from the Yagur. This project, with an investment of $\$ 1.4$ billion, was promoted as part of a national strategy for touristic development. Unfortunately, much of the collective lands of the Oukaimeden, managed and made productive through the agdal system, would end up buried under iron and cement if such a project were implemented. With such proposals, it appears to most locals that large tourism development projects explicitly or implicitly seek to break down local heritage. As is wellknown from experiences in other regions (Boissevain 2001; Picard and Wood 1997), such projects most frequently lead to a radical transformation of local culture. Though still relatively untransformed toward tourism, the Yagur is already a target of international tourist agencies operating in the area, and the possibility that a similarly massive tourism project could be proposed for the area is on every local's mind. This is in fact a territory that offers the experience of an ancient but still minimally altered natural and cultural heritage, and is the closest of all big pastoral agdals to the tourist center ofMarrakesh.

\section{The Mesioui Sufi Saints and Sidi Boujmaa}

It is well-known that in Morocco religious practices and beliefs regarding different sufi_saints, their descendants, their tombs, as well as genies, wizards, clairvoyants, and others of the sort, are common trade among all types of people, including many with high education levels. While globalization has undermined these religious practices and beliefs in recent decades, even in the High Atlas Mountains, the system of the Mesioua sufi saints remains particularly alive and diverse. In the Yagur territory, there are believed to exist a group of at least 360 sufi saints. Some of them have tombs located inside and outside the Yagur, but others have no fixed place of burial, just a vague spatial reference. Locals say that the spirits of the 360 sufi saints constantly patrol the territory jointly and punish those who do not demonstrate an appropriate use of and respect towards the agdal.

However, according to local legends, the sufi saint Sidi Boujmaa was given 'the key of the Yagur' by the other sufi saints and is considered the patron saint and the main 'keeper' of the territory and its rules. Sidi Boujmaa is also the name given to the mystic brotherhood (zawiya) that emerged after the patron saint's death and is composed of his male descendants, 
as is usual with all importrant sufi saints. The village inhabited by these male descendants, their wives and children, also has the name of Sidi Boujmaa. The importance of Sidi Boujmaa and his descendants for the mountain Mesioui is rooted in their role as arbitrators and peacemakers in local conflicts, especially in those concerning the agdal of Yagur. Their supposed purity and receipt of blessing (baraka) from God put them in a favorable position for this. As part of their role as arbitrators and peacemakers, the descendants of Sidi Boujmaa announced the lifting of the agdal prohibition every year until the 1960s. This ritual announcement occurred at the upper Zat valley's weekly market just before the first Friday of Berber summer, which starts on the 28th of July. As Friday is the main Muslim day of prayer, and the saint's descendants were regarded as saints themselves, this was a way of doubling the blessing and legitimation of the agdal opening rules, so as to ensure a prosperous season in the high mountain pastures. Until then, the great majority of the mountain Mesioui recognized the sufi saint Sidi Boujmaa as the main protector and guarantor of the respect toward the rules and of the functioning of the collective agdal system and territory of the Yagur.

Nevertheless, at the same time that locals agreed on Sidi Boujmaa's protection for the whole of the Yagur, each tribal faction also claimed its own sufi saint's protection of their territory. These saints' presences are most often represented by small mausoleums or similar constructions, often hosting the tomb of the faction's main sufi saint. These monuments can still be found today, either directly in the uninhabited area of the Yagur or at its borders. This practice is designed to indicate the territorial property of each group in the Yagur, by keeping symbolic watch over its access routes and its frontiers (Simenel 2011). As can be observed in Figure 2, there is a saint's tomb in the territory of the Ait Wagoustite faction (Sidi Boujmaa), another representing the Ait Zat at the highest point of the Yagur (Sidi Meltsene on the Meltsene peak, at nearly 3,600 meters above sea level.), the Ait Inzal also have a holy place referring to their saint (Sidi Hamed El Wafi), and the Ait Oucheg have a female saint's tomb (Lalla Amina Hamou). In total there are four major Yagur sufi saints represented by a monument of some type, corresponding each to a different tribal faction. Only the Ait Tighdouine have none and this may be linked to the fact that the Ait Tighdouine's main lowland territory, where they pass most of the year, is the furthest of all five factions from the Yagur. In addition, they are the only faction without any direct territorial continuity with the Yagur. One of the main goals of this sufi saint system and its monuments was to reinforce a certain territorial order and the consolidation of the frontiers, as well as to grant respect toward the agdal. The belief in Sidi Boujmaa as well as the rest of Mesioui sufi saints helped to assure this.

\section{An Eco-Cosmological and Epistemological System Undergoing Major Changes}

The traditional system of the sufi saints and the agdals that I have described above, has undergone very particular and intense transformations in the last half century. After the independence of Morocco in 1956, and especially from the 1960s onward, outside influences became increasingly noticeable in the region. State officials and civil servants came first, followed by public schools, radio stations, television, official discourses on conservation, Imams, the spread of a more orthodox and rigid Islam, international tourism and NGO representatives; all of them, in their own way, tended to increasingly stigmatize the figure of the sufi saints as archaic, useless and even anti-Islamic. Today, when the different tribal faction representatives involved in an agdal opening decision cannot reach an agreement among themselves, the State official representing the Ministry of the Interior (the Caid), acts as a referee and thus assumes the old arbitrator and peace-making role of the sufi saints.

The result of this is that over the past five decades, belief in the saints' (particularly big tribal saints such as Sidi Boujmaa's) baraka has dissipated, especially among the younger half 
of the population (Dominguez 2010; Dominguez et al. 2010). For example, some people still believe in divine punishment if collectively agreed upon agdal prohibitions are not respected. But the majority now attributes retribution to God without the mediation of the saints, just as the new rhetoric mandates. Moreover, the saints are frequently the subject of jokes and denigration. Also, the great majority of the population no longer believes that the Sidi Boujmaa descendants' announcement of the opening of the Yagur can bless the community or help assure the socio-ecological sustainability for which the agdal was designed. Pressure from the outside world has contributed to weakening sufi saints' power in the management and recognition of the traditional agro-pastoral systems of the agdals.

Today, the tribal factions decide upon a different opening date of the agdal of Yagur every year, independently of the sufi saints' tradition, and now forbid the once prominent announcement of the old sacred opening by the Sidi Boujmaa descendants. At the same time, the opening date of the Yagur has occurred at least one and even two months early sometimes, mainly depending on the annual rainfall. As the time for plant production and reproduction is increasingly minimized, overgrazing and the homogenization of the flora are also increasing (Alaoui 2009). As well (Hardin 1968), open-access or early-openings of common pastures are, in the short term, more beneficial for the bigger livestock owners than the smaller ones since those with more numerous herds are able to extract for 'individual' profit from the 'common' pool more natural resource per unit of time than smaller ones. In this way, the disparity between economic classes tends to be accentuated through this process (Dominguez 2010).

Another source of instability (Demay 2004; Dominguez and Hammi 2010) of the socioecological system of the Yagur agdal can be seen through the case of the Ait Ikis, a small community of Yagur users belonging to the Mesioua tribe, made up of about 700 people dispersed between four hamlets in a territory of approximately twenty square kilometers. Like other mountain Mesioui, since the 1960s certain Ait Ikis migrated to France to work in coal and iron mines and other contract work. Their savings allowed them to join the ranks of a new local elite back in Morocco who started investing in pastoral activity and agricultural innovation. These changes in the social hierarchy have coincided with zoo-technical improvements in livestock promoted by the Moroccan State. For instance, the Sardi, a new breed of sheep, was introduced into the region and today all the sheep of the Ait Ikis have been cross-bred with it. This breed is more productive when it is well-nourished, especially with cereal, but worse at walking and thus more apt for low movement stalling than for transhumance, the traditional way of production so linked to the agdals and the sufi saints.

During the last five decades mono-specific cereal fields (mainly barley but also wheat) have also spread exponentially over the richest pastures of the Ait Ikis' part of the Yagur. This has taken place mainly to feed the new Sardi sheep (Demay 2004). As a result, cultivated soil on the Yagur doubled only in the 26 years from 1980 to 2006 (Figures 3 and 4). This trend continues today and is leading to the disappearance of many pastoral plants (Dominguez 2010). Another consequence is that in years of drought, there is pressure from the richest livestock owners to prematurely open the small agdals ${ }^{6}$ that surround the Ait Ikis' part of the Yagur and which usually provide supplemental fodder when the big pastures of Yagur are worn out after too much summer grazing, especially in dry years. Locals affirm that in the long term this also results in diminished respect toward the agdal prohibition on the Yagur, or an invasion of the rangelands of neighboring douars. Therefore, at present there are serious tensions between villages and, particularly, between the richest agro-pastoralists and the rest of the Ait Ikis people. In fact, only the largest livestock owners, who consequently make the most of the available grass if an early opening is allowed, push for these early openings, while the poorer

\footnotetext{
${ }^{6}$ Apart from the big Yagur agdal, the Ait Ikis base their agro-pastoral economy on nearly ten other small agdal prohibitions concerning different resources.
} 
majority generally opposes the pressure of the richer ones. Thus, tensions over the different agdal prohibitions and the access to different pastoral resources are manifest yearly in the village jmaas and to a greater extent than before, having now no symbolic protection from the old saints' narratives of respect toward the agdal governance system.

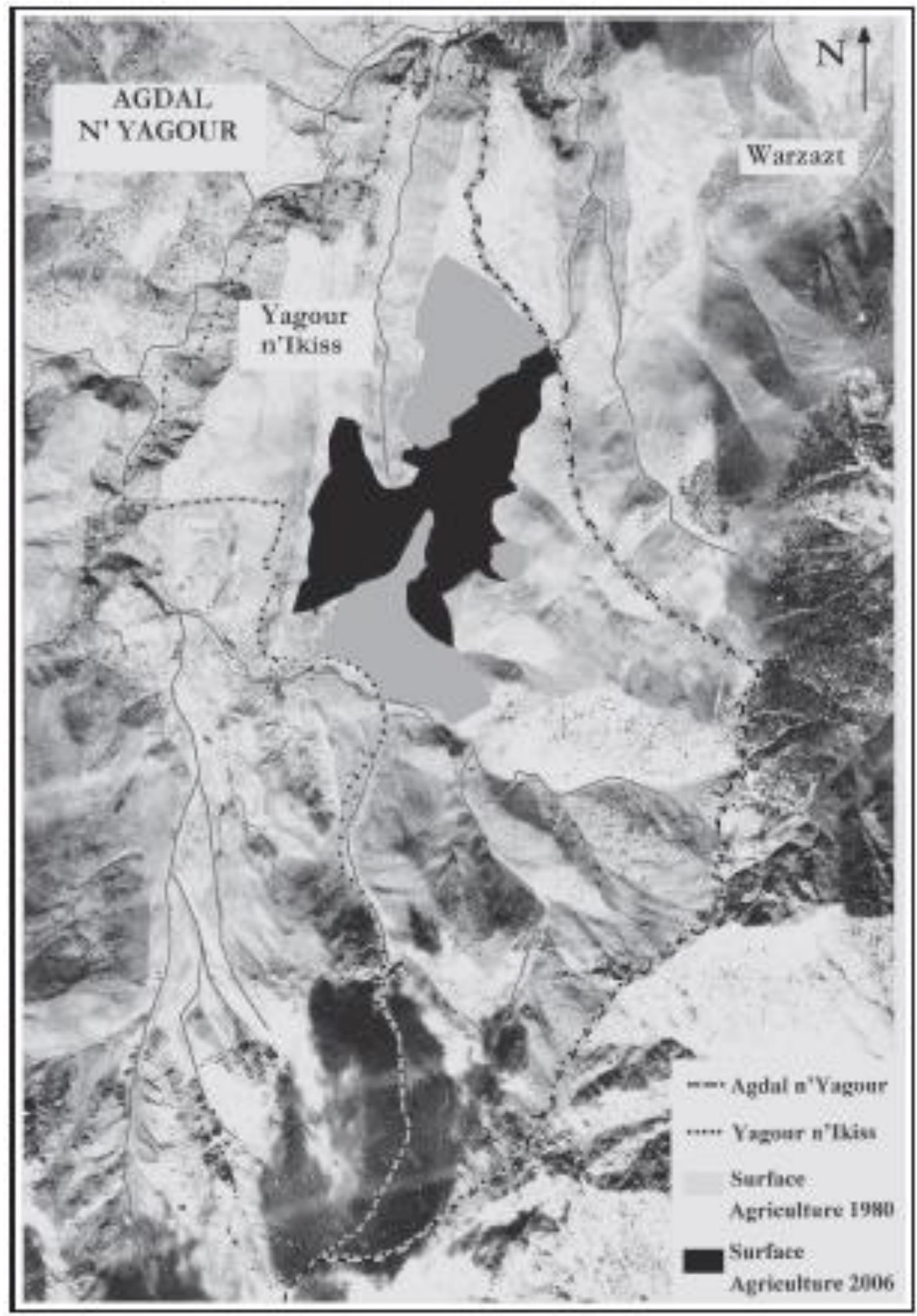

Figure 3: Advancement of the cultivated area with the Ait Ikis' Yagur marked by a line of dots (map based on aerial photography $1 / 20000$, provided by project AGDAL, IFB $\mathrm{n}^{\circ} 2886$ ). 


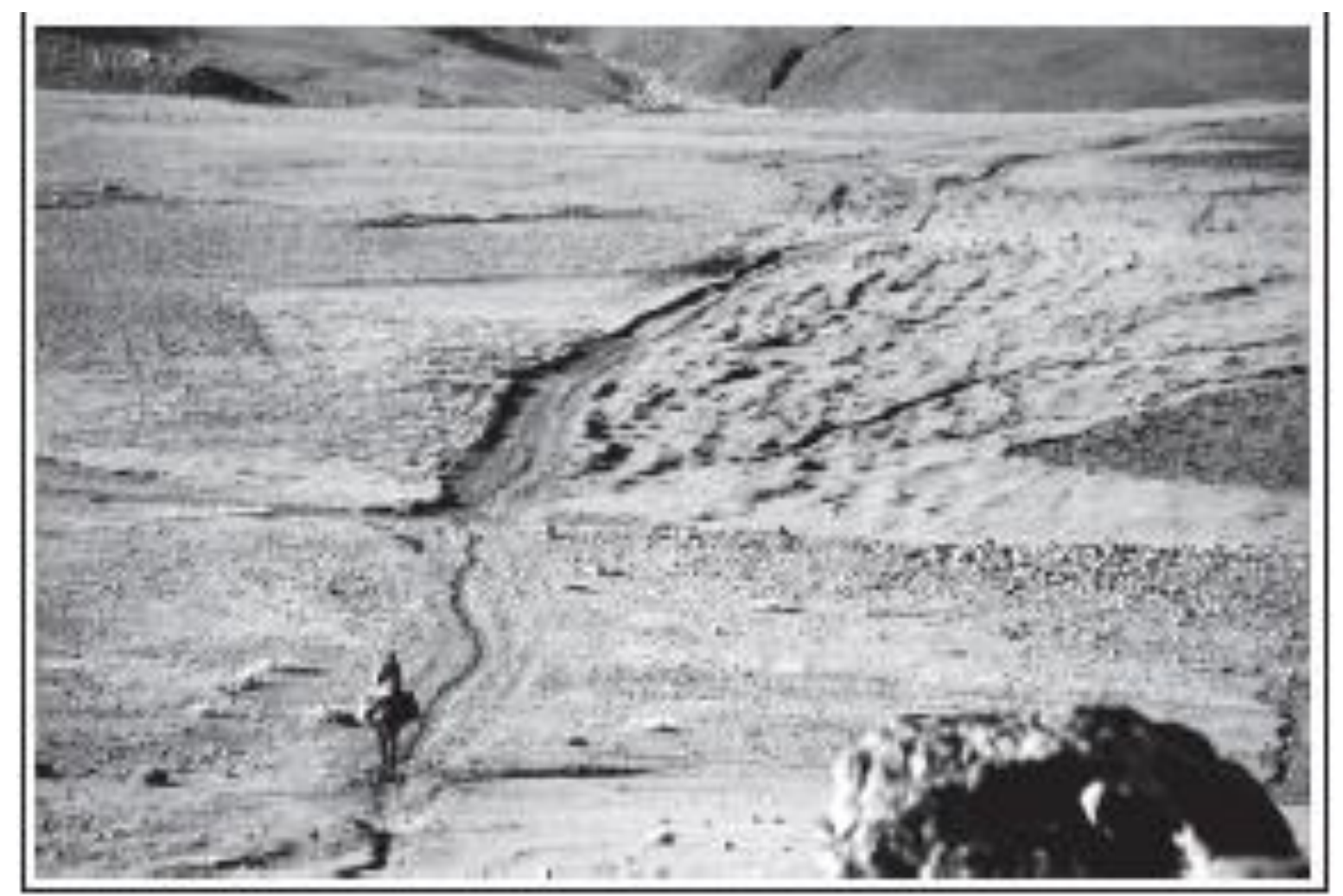

Figure 4: Cultivated and overgrazed aspect of the Yagur in 2006 (photo Pierre Perrou).

It seems no coincidence that once the relevance of Sidi Boujmaa for the local population declined and the new breeds were introduced to the local flocks, both in the 1960s, the traditional agdal dates were deactivated, the opening was moved forward by one to two months, and cereal production spread exponentially on the richest pastures of the Yagur (Dominguez 2010). The shift of cultural values away from the protection and authority of sufi saints and toward a market economy made it easier to bring the opening dates of the agdal forward and usurp the collective grasslands for private crop fields and Sardi breeding. As a local key informant explained 'The Yagur is the mouchayia [common property] of the group. But now it is like a room that we share and if you smoke in it you can't stop the others from smoking. Either no one smokes or we all smoke'.

\section{Discussion}

For some decades now, pastoralism in the mountains of Mediterranean Europe has been seen as both a key factor in the formation of tourist landscapes and as an essential tool in the maintenance of biodiversity (Hubert 1991). However, in Morocco, pastoralism is still seen as a major cause of degradation and impoverishment. Several researchers have identified reasons for this. Warren (1995) notes that Moroccan government officials who do not adhere to the old equilibrium-carrying capacity model may fail to advance in their careers. Indeed, the official discourse on conservation is based on 'restoration' of degraded lands through succession toward climax botanical communities, and this is constantly reproduced in official publications (Ouassou et al. 2006). Thus, officials of the ministry of agriculture (ORMVA) are generally driven by the old-fashioned (Boudy 1955) but still well-established and predominant Malthusian ideology that degradation is due to inferior local management, overpopulation, and overgrazing. The officials of the Moroccan top-down managerial bureaucracy generally 
disdain local knowledge and treat herders as chaotic and irrational (Casciarri and Chatty 2006). This undermining of the legitimacy of traditional institutions to govern local resources serves as a means by which the State and its main actors control local populations (Venema and Mguild 2003). Thus, Moroccan officials continue to assert that rangelands are degraded by locals' incompetence and need to be restored to 'equilibrium' through the action of the knowledgeable State.

Environmental policy in Morocco is mired not only in outdated scientific theory, but in strongly contested theories of environmental economics. Hardin's (1968) 'Tragedy of the Commons' advocated top-down state management or privatization of resources held in common. But as shown in this article and by many others since, this was based on a nonempirical assumption and the mistaken conflation of common-property with free open-access and a lack of property rights (Berkes et al. 1989). Much empirical and theoretical work has been carried out in recent decades to rectify this erroneous and damaging assumption (McCay and Acheson 1987). Most of these studies have focused on the role of institutions in governing local resources. For example, Ostrom (1990) found that communities with a shared interest in a resource frequently managed to exclude others from using it and came up with various rules for equitable and sustainable use. But the need to highlight the role of local populations' natural resource managerial capacities in relation to the religious beliefs and practices linked to these has also become evident and increasingly important for environmental conservation and sustainable development in such communities (Berkes 2008).

My analysis of the agdal of Yagur and the zawiya of Sidi Boujmaa supports these claims with fresh data, which confirms the conclusions of similar research in other areas of the world (Simenel 2004; Auclair and Alifriqui 2012). As we have seen, traditionally the prohibition period imposed by the agdal of Yagur was strongly legitimized and supported by long-held religious beliefs among the descendants of the main local sufi saint, Sidi Boujmaa. Until the 1960s the lifting of the annual agdal prohibition was announced by them, hence sacralizing and 'securing' the dates of the prohibition. At the same time, Sidi Boujmaa and the other minor faction saints contributed to ensure the frontiers within the common territory. Nevertheless, as observed in this article, for different historical reasons having influenced the local cosmologies and epistemologies of nature throughout the last five decades, most locals today no longer believe that the annual lifting of the agdal has to be announced by the saint's descendants in order to be effective and receive the blessing of God. At the same time, access to the Yagur now begins before its traditional date yielding negative ecological consequences for the flora, as locals and scientists recognize (Alaoui 2009; Dominguez and Hammi 2010), and increasing the socio-economic inequalities among the local population (Domiguez 2010). Similarly, large areas of pasture, once believed by most locals to be protected and preserved by the sufi saints, are now being used for intensive agriculture to feed the Sardi sheep, which if well complemented with grain, fetch a higher market price than the old free range Beldi race (Demay 2004). This is possible thanks to the expanding demand for red meat from the growing tourism industry of neighboring Marrakesh. This causes negative ecological and socio-economic consequences such as the loss of pastures and its consequent soil loss, as well as increasing socio-economic inequalities within the local community (Dominguez 2010).

\section{Conclusion}

Through the observations described in this article, we can conclude that, strained by the forces of globalization, the replacement of the local cosmology and the decline of the traditional agdal natural resource management system of the Yagur are interlinked, at the same time that they are key factors leading to increasing environmental degradation and social inequalities in the area. In the particular case of Morocco (Auclair and Alifriqui 2012), as in most of the countries 
of the Southern Mediterranean basin (Auclair 1998), mountain pastoralists still depend greatly on local natural resources for their subsistence. Nevertheless, at least since colonial times, they are most frequently seen as hosts of a 'lower' culture and religion and, paradoxically, the main factor responsible for the degradation of the environment upon which they rely (Davis 2005; Benabid 2000). However, here we have seen that the Mesoui pastoralists, through their traditional agdal of Yagur, were able to control environmental degradation and social inequality. Only when their endogenously and culturally embedded eco-theological system of the agdal was pushed to a crisis, precisely by the same actors that denigrated it before having real scientific data about its utility, did environmental degradation and social inequality start growing exponentially in the Aïk Ikiss community (Dominguez 2010).

The religious regulatory regime described above appeared to be interdependent with the agdal governance system, providing protection of the local environment and biodiversity while producing and reproducing local society in a more equal and sustainable way. The evidence presented in this article highlights the need to integrate community-based management systems, particularly those embedded in a long cultural history and having acquired the form of a certain spiritual ecology (Sponsel 2012), within programs of biodiversity conservation and human development through the participation of existing religious authorities and managerial institutions. At the same time, the present study of the agdal institution implicitly adds weight to the criticism of sustainable development programs that are derived from non-local, distant government and non-governmental institutions that work within classic fortress-conservation and neoliberal discourses (Snodgrass and Tiedje 2008). Indeed, the objectives and results of modern local community-based conservation programs and traditional systems such as the agdals often match or complement each other (Smith and Wishnie 2000). The recognition by the scientific community of this local governance and religious tradition in terms of its potential for human development and environmental conservation could encourage Moroccan administrations, the media, civil society and international organizations to do the same, and hence support and promote these centuries-old existing eco-religious systems.

\section{Acknowledgements}

This research was funded initially by the programme AGDAL (Biodiversité et gestion communautaire de l'accès aux ressources sylvopastorales/I.F.B - $\mathrm{n}^{\circ} 2886$ of I.R.D. funding), and subsequently by the Agence Universitaire de la Francophonie (AUF), the UNESCO, the Agencia Española de Cooperación Internacional y Desarrollo (AECID), the programme Marie Curie MIRG-CT-2006-036532 and the Agència de Gestió d'Ajuts Universitaris $i$ de Recerca (AGAUR). Parts of this text have been translated from French to English thanks to the financial support of the research group Antropologia $i$ Historia de la Construcció de les Identitats Socials i Politiques (AHCISP) of the Universitat Autònoma de Barcelona. I also thank Iñaki Dominguez and Rajindra Puri for their editing of the English of the pre-final versions. At the same time I would like to thank Simohamed Ait Bella, Taoufik El-Khalili and Mjid Mourad for their excellent work as translators and researchers, all the members of the local NGO Association des amis du Zat and especially its president Ahmed Bellaoui, for having provided so many human resources and infrastructure to reach the local communities, as well as all the informants who were so patient and cooperative.

\section{References}

Alaoui, Safia. 2009. 'Les Pelouses Humides dans le Haut Atlas: Biodiversité Végétale, Dynamique Spatiale et Pratiques de Gestion Coutumière'. PhD Diss.: Université Cadi Ayad, Marrakesh. 
Auclair, Laurent. 2001. 'Espaces Agraires et Environnement en Tunisie: La Permanence des Cadres Spatiaux au Cours du $20^{\text {ème }}$ Siècle', in M. Elloumi and A. Mhiri (eds.), Centenaire de l'INAT 1998: Actes du 2ème séminaire international mutations des sociétés rurales et développement durable dans les pays de la rive sud de la Mediterranée (Tunis: INAT): 43-70.

Auclair, Laurent, and Mohamed AlIfriqui (eds.). 2006. Rapport d'achèvement des travaux du programme 'Les agdal du Haut Atlas marocain: Biodiversité et gestion communautaire de l'accès aux resources forestiers et pastorales' (Marseille: Laboratoire PopulationEnvironnement-Développement).

Auclair, Laurent, and Mohamed AlIfriqui (dirs.). 2012. Agdal: Patrimoine socio-écologique de l'Atlas marocain (Rabat: IRD-IRCAM).

Baland, Jean-Marie, and Jean-Philippe Platteau. 1999. 'The Ambiguous Impact of Inequality on Local Resource Management', World Development 27.5: 773-88.

Bellaoui, Ahmed. 1989. 'Les pays de l'Adrar-n-Dern: Etude géographique du Haut Atlas de Marrakesh'. PhD Diss.:Université de Tours, Tours.

Benabid, Abdelmalek. 2000. Flore et Écosystèmes du Maroc: Évaluation et Préservation de la Biodiversité (Paris: Éditions Ibis Press).

Berkes, Fikret, David Feeny, Bonnie J. McCay, and James M. Acheson. 1989. 'The Benefits of the Commons', Nature 340: 91-93.

Berkes, Fikret. 2008. Sacred Ecology: Traditional Ecological Knowledge and Management Systems (London: Routledge).

Boissevain, Jeremy. 2001. 'Insiders and Outsiders: Mass Tourism and the European South', in D. Albera, A. Blok and C. Bromberger (eds.), L'Anthropologie de la méditerranée (Paris: Edition Maisonneuve et Larose / Maison Méditérannéene des Sciences de l'Homme): 685-709.

Boudy, Paul. 1955. Économie Forestière Nord-Africaine (Paris: Éditions Larose).

Casciarri, Barbara, and Dawn Chatty. 2006. 'Coping with Shrinking Spaces: The Ait Unzar Pastoralists of South-Eastern Morocco', in D. Chatty (ed.), Nomadic Societies in the Middle East and North Africa: Entering the 21st century (New York: Brill): 393-430.

Demay, Sébastien. 2004. Mémoire de DAA agronomie 'Diagnostic agraire dans le Haut Atlas marocain: Territoire des Aït Ikis' (Paris: INA Paris-Grignon).

Davis, Diana K. 2005. 'Potential Forests: Degradation Narratives, Science, and Environmental Policy in Protectorate Morocco, 1912-1956', Environmental History 10.2: 211-238.

Descola, Philippe. 2005. Par-delà nature et culture (Paris: Gallimard).

Dominguez, Pablo. 2010. 'Approche multidisciplinaire d'un système traditionnel de gestion des ressources naturelles communautaires: L'agdal pastoral du Yagur (Haut Atlas marocain)'. 
PhD Diss.: École des Hautes Études en Sciences Sociales / Universitat Autònoma de Barcelona. Online : www.tdx.cat/bitstream/10803/79093/1/pdg1de1.pdf.

Dominguez, Pablo, Francisco Zorondo, and Victoria Reyes-Garcia. 2010. 'Relationships Between Saints' Beliefs and Mountain Pasture Uses', Human Ecology, An Interdisciplinary Journal 38: 351-362.

Dominguez, Pablo, and Sanae Hammi. 2010. 'L'agdal du Yagour, écologie et pastoralisme', in K. Fernández (ed.), Ecología y Pastoralismo (Donostia: Koldo Michelena): 34-56.

El Gueroua, Abdellaziz. 2005. Rapport de recherche 'Analyse des structures institutionnelles coutumières dans la vallée Ä̈t Bouguemez: leur rôle en matière de gestion des ressources renouvelables et les transformations en cours' (Marrakesh: Laboratoire PopulationEnvironnement-Développement).

Gellner, Ernest. 1969. Saints of the Atlas (London: Weidenfield and Nicholson).

Genin, Didier, Loïc Kerautret, Sanae Hammi, and Mohamed AlIfriqui. 2012. 'Biodiversité et pratiques d'agdal: un élément de l'environnement à l'épreuve de ses fonctions d'utilité pour les sociétés rurales du Haut Atlas', in L. Auclair and M. Alifriqui (eds.), Agdal. Patrimoine socio-écologique de l'Atlas marocain (Rabat: IRD-IRCAM): 93-125.

Hammi, Sanae, Mohamed AlIfriqui, Vincent Simonneaux, Laurent Auclair and Nicolas Montès. 2007. 'Évolution des recouvrements forestiers et de l'occupation des sols entre 1964 et 2002 dans la haute vallée des Ait Bouguemez (Haut Atlas Central)', Sécheresse 18.4: 271277.

Hardin, Garrett. 1968. 'The Tragedy of the Commons', Science 162: 1243-1248.

Hubert, Bernard. 1991. 'Comment raisonner de manière systèmatique l'utilisation du territoire pastoral?', Actes IVe Congrès International Terres de Parcours (Montpellier: Association Française de Pastoralisme).16: 147-156.

Kerautret, Loïc. 2005. Mémoire de Maîtrise 'Entre Agdal et Moucharika' (Marseille: Université de Provence).

Lafuente, Frédérique. 1968. 'La vie humaine dans un groupement berbère du Haut Atlas de Marrakesh: les Aït Oucheg', Revue de Géographie du Maroc 14: 71-116.

Lansing, Stephen. 1987. 'Balinese "Water Temples" and the Management of Irrigation', American Anthropologist, New Series 89.2: 326-341.

McCay, Bonnie J., and James M. Acheson. 1987. The Question of the Commons: The Culture and Ecology of Communal Resources (Tuscon: University of Arizona Press).

Ministère de 1'Agriculture. 1977. Carte du Maroc 1: 50.000, Feuille NH-29-XXIII-1d, Arbi'a Tighadwiyn (Rabat : Division de la Carte).

Montès, Nicolas, Christine Ballini, Magalli Deschamps-Cottin, Sanae Hammi, and Valérie Bertaudière-Montès. 2012. 'Conséquences écologiques de la gestion coutumière des espaces 
forestiers dans le Haut Atlas marocain. Le cas de la vallée des Ayt Bouguemmez', in L. Auclair and M. Alifriqui (eds.), Agdal. Patrimoine socio-écologique de l'Atlas marocain (Rabat: IRDIRCAM): 149-62.

Ouassou, Abdellah, Tayeb H. Amziane, and Lahcen Lajouad. 2006. 'State of Natural Resources Degradation', in W. G. Kepner, J. L. Rubio, D. A. Mouat and F. Pedrazzini (eds.), Morocco and Plan of Action for Desertification and Drought Control: Desertification in the Mediterranean Region: A Security Issue (Dordrecht: Springer): 251-68.

Ostrom, Elinor. 1990. Governing the Commons. The Evolution of Institutions for Collective Action (Cambridge: Cambridge University Press).

5412: $278-82$.

1999. 'Revisiting the Commons: Local Lessons, Global Challenges', Science 284.

Picard, Michel, and Robert E. Wood (eds.). 1997. Tourism, Ethnicity, and the State in Asian and Pacific Societies (Honolulu: University of Hawaï Press).

Posey, Darrell, and William Balee. 1989. Resource Management in Amazonia: Indigenous and Folk Strategies (New York: The New York Botanical Garden).

Rappaport, Roy A. 1968. Pigs for the Ancestors: Ritual in the Ecology of a New Guinea People (London: Yale University Press).

Redford, Kent H. 2010. 'The Ecologically Noble Savage', Cultural Survival Quarterly Magazine, 15.1: http://www.culturalsurvival.org/ourpublications/csq/article/the-ecologicallynoble-savage

Simenel, Romain. 2004. 'De la forêt du saint au pâturage des chrétiens (Perception du paysage et gestion du couvert végétal chez les Aït Baarmran du Sud Marocain)', Cahiers de recherche du CJB 1: 119-133.

2011. L'origine est aux frontières: Les Aït Ba'amran, un exil en terre d'arganiers (Sud Maroc) (Paris: Éditions de la Maison des sciences de l'homme / CNRS Éditions).

Snodgrass, Jeffrey G., and Kristina Tiedje. 2008. 'Indigenous Nature Reverence and Conservation: Seven Ways of Transcending an Unnecessary Dichtomy', Journal of the Study of Religion, Nature and Culture 2.1: 6-29.

Sponsel, Leslie. 2012. Spiritual Ecology: A Quiet Revolution (Santa Barbara: Praeger).

Steward, Julian. 1955. Theory of Culture Change: The Methodology of Multilinear Evolution (Chicago: University of Illinois Press).

Toledo, Victor M. 1992. 'What is Ethnoecology? Origins, Scope, and Implications of a Rising Discipline', Etnoecologica 1: 5-21.

Venema, Bernhard, and Ali Mguild. 2003. 'Access to land and Berber ethnicity in the Middle Atlas, Morocco', Journal Middle Eastern Studies 39.1: 35-53. 
Warren, Adam. 1995. 'Changing Understandings of African Pastoralism and the Nature of Environmental Paradigms', Transactions of the Institute of British Geographers 20.2: 193-203. 